\title{
The endocrine environment of the human oocyte
}

\author{
E. A. Lenton, H. King, E. J. Thomas, S. K. Smith*, R. I. McLachlan†, \\ S. MacNeil $\ddagger$ and I. D. Cooke
}

University Department of Obstetrics \& Gynaecology, Jessop Hospital, Sheffield S3 7RE, U.K.; ${ }^{*}$ MRC Unit of Reproductive Biology, 37 Chalmers Street, University of Edinburgh, Edinburgh EH3 9EW, U.K.; †Department of Anatomy, Monash University, Clayton, Victoria 3168, Australia; and $\ddagger$ Department of Medicine, Clinical Sciences Centre, Northern General Hospital, Sheffield S5 $7 A U, U . K$.

Keywords: follicular fluid; oocyte maturation; steroids; gonadotrophins; inhibin; prolactin; cAMP

\section{Introduction}

Follicular fluid is a unique body fluid containing a large number of biochemical components, some in extremely high concentrations, whilst in the middle of this relatively isolated biological compartment lies the arrested oocyte awaiting the signals to resume meiosis and progress towards timely ovulation. Delineation of these signals poses a challenging task. While there have been numerous reports on the concentrations of various steroids and peptides in follicular fluid after both natural and stimulated follicular growth and, similarly, the relationship between various components of oocyte maturation and the perceived signal has been studied in depth, the precise chronology of the endocrine changes relative to the sequence of oocyte maturation has not been systematically evaluated. Ideally the changing endocrine profile of the late preovulatory follicle would be best investigated by repeated frequent sampling (say every $2 \mathrm{~h}$ ) of a single follicle. Unfortunately in the human such a longitudinal study would be difficult and so as an alternative approach we have considered the pattern of simultaneous endocrine changes in a cross-sectional group of follicles timed with respect to a common event (the start of the endogenous LH surge). The study of human follicular fluid is relatively simple because of the large volumes $(2-8 \mathrm{ml})$ present in a preovulatory follicle but precise timing of the endogenous LH surge is more difficult due to the problems of frequent blood sampling. An alternative although slightly less precise method is to measure LH in frequent urine collections.

Finally, if the primary reason for aspirating the follicle was to obtain an oocyte for in-vitro fertilization, then it becomes unethical to attempt to obtain follicular fluid before $20-25 \mathrm{~h}$ from the start of the LH surge since it is unlikely that sufficiently mature fertilizable oocytes would be obtained. Therefore, to study the chronobiology of human follicular fluid from before the onset of the spontaneous LH surge until the time of ovulation, two sources of patients are required. For the early follicular fluid, patients coming into hospital for laparoscopic sterilization were recruited whilst later follicular fluids were obtained during the course of an in-vitro fertilization performed in unstimulated or natural cycles.

\section{Materials and Methods}

\section{Collection of follicular fluids}

Follicular fluid was aspirated from the dominant follicle either just before the start of the expected LH surge or at defined times after the start of the surge but before spontaneous follicular rupture (ovulation). For the early follicles, 
i.e. those just before or within $20 \mathrm{~h}$ of the start of the LH surge, the largest, presumptively dominant follicle was aspirated during the course of a diagnostic laparoscopy, or at the time of laparoscopic sterilization. These subjects had given consent for the aspiration of follicular contents, and had submitted to twice daily blood sampling in order to determine whether the LH surge had begun by the time of aspiration. Blood samples were assayed for LH and oestradiol concentrations. Follicles classed as before the LH surge were obtained from women who had high circulating concentrations of oestradiol in association with a large ( $>17 \mathrm{~mm}$ diameter) follicle, but in whom there was no increase in plasma LH by the time of the laparoscopy. It is difficult to assess exactly how many hours before the LH surge these individuals were because it has been shown that aspiration of the dominant follicle can produce temporal alterations in the timing of the expected surge (Lenton et al., 1985). The follicles after the start of the LH surge were obtained from women in whom plasma oestradiol concentrations were still high, although a clear increase in LH had occurred within 10 or $20 \mathrm{~h}$ of the time of operation. No attempt was made to classify these follicles more closely because the monitoring blood samples had only been obtained twice a day.

Later (i.e. 20-35 h) follicular fluids were obtained during the course of oocyte collection for the purpose of in-vitro fertilization. Neither these, nor the above laparoscopy subjects had received any form of hormonal stimulation, and all gave a history of regular, apparently ovulatory cycles. In the in-vitro fertilization patients follicular aspiration was performed as an out-patient procedure using ultrasonography, and aspirations were more accurately timed with respect to the start of the spontaneous $\mathrm{LH}$ surge. This was achieved by 4-5-h urine collections, equally spaced over the $24 \mathrm{~h}$ which were then assessed for LH content using LH dipsticks (Ovustick: Medimar Laboratories, 17 The Queensway, Chalfont St Peter, Bucks S19 8NB, U.K.). These patients were also being scanned daily, and the start of the LH surge was defined as the time of the beginning of the first 4-h urine collection with detectable LH levels, provided that semi-quantitative LH levels continued to rise serially over the next $12-24 \mathrm{~h}$. It was appreciated that the onset of the urinary LH surge detected in this way lagged behind the plasma LH surge by a few hours (E. A. Lenton, S. Amos, G. Lanjou \& I. D. Cooke, unpublished observations) but this delay was well within the age bands selected for grouping the follicular fluids. It was therefore considered that, for the purpose of the study presented here, follicular fluids which have been grouped into 10-h age bands were equivalent regardless of whether the surge was detected by urinary or plasma LH measurements.

Finally, a small group of 4 follicular fluids which were assessed as being more than $40 \mathrm{~h}$ from the start of the LH surge is included. One of these follicles was from a patient who regularly demonstrated luteinized unruptured follicles, but in the other 3 patients follicular rupture had been artificially blocked by the administration of indomethacin (Indocid: Thomas Morson Pharmaceuticals, Hoddesdon, Herts EN11 9BU, U.K.) (100-200 mg in divided doses for 24-48 h). These follicles are referred to as 'post-ovulatory' follicles. In addition, 2 of the 8 follicles in the 35-40-h group were also obtained after indomethacin administration (Murdoch \& Dunn, 1983).

Follicular fluids were stored frozen at $-20^{\circ} \mathrm{C}$ until assayed for the steroids oestradiol, androstenedione, testosterone and progesterone and the peptides prolactin, LH, FSH and inhibin. Concentrations of cAMP were also measured.

\section{Selection of normal follicular fluids}

The follicular fluids discussed here were selected from a larger series of follicular fluid samples on the basis of the following criteria.

(1) The onset of the LH surge (particularly applicable to the urinary monitoring) had to be clear and unequivocal.

(2) All follicles had to be assayed for at least 6 of the 8 endocrine measures under discussion (in fact for $86 \%$ of the follicular fluids all 8 measurements were available).

(3) The numbers of follicular fluids had to be equal in each age group and this number was arbitrarily set at 8 per group except for the oldest follicles in the 'greater than $40 \mathrm{~h}$ ' group, for which only 4 follicular fluids were available.

(4) All follicles had to be demonstrably active preovulatory follicles (oestradiol concentrations $>2000 \mathrm{ng} / \mathrm{ml}$ or progesterone concentrations $>5000 \mathrm{ng} / \mathrm{ml}$, and luteinized granulosa cells evident).

Samples from 44 follicles form the basis of the data presented here. In each of the figures, the respective follicular fluid concentrations have been shown individually, but in the same sequence throughout, in order to demonstrate the extent of the variability within and between age groups, and between different hormone measurements on the same fluid. The mean concentrations at each interval are, however, given in Table 1, relative to the equivalent concentration in the peripheral circulation at mid-cycle.

\section{Hormone measurement}

All steroid measurements were made using commercially available direct (i.e. non-extraction) radioimmunoassay kits. Follicular fluids were first diluted (v/v) in appropriate hormone-free serum as follows: oestradiol 1:10 000, progesterone 1:1000, androstenedione 1:250 and testosterone 1:25. The radioimmunoassay kits were obtained from Steranti Research Ltd, St Albans, Herts AL1 1TA (oestradiol, ER-155 and androstenedione, ER-750 and testosterone ER-355) and from RIA UK Ltd, Armstrong Estate, Tyne \& Wear NE37 1PP (progesterone, Gamma-B). Sensitivities at the above dilutions and inter-assay coefficients of variation were $100 \mathrm{ng} / \mathrm{ml}$ and $5 \cdot 1 \%$ (oestradiol), $600 \mathrm{ng} / \mathrm{ml}$ and $11.0 \%$ (progesterone), $10 \mathrm{ng} / \mathrm{ml}$ and $7.0 \%$ (androstenedione) and $2 \mathrm{ng} / \mathrm{ml}$ and $15.0 \%$ (testosterone).

The peptides LH, FSH and prolactin were measured using monoclonal antibody-based immunoradiometric assays (Maiaclone) from Serono Diagnostics Ltd, 21 Woking Business Park, Woking, Surrey GU12 5JY. Follicular 
fluids were again diluted 1:2 (v/v) with control (hormone-free) serum to avoid any error due to the slightly different protein spectrum in follicular fluid compared with plasma/serum. Sensitivities and interassay coefficients of variation were $0.3 \mathrm{u} / 1$ and $3.9 \%(\mathrm{LH}) ; 0.3 \mathrm{u} / 1$ and $6 \cdot 8 \%$ (FSH) and $12 \mathrm{mu} / 1$ and $5 \cdot 2 \%$ (prolactin).

The inhibin measurements were performed with a previously described radioimmunoassay (McLachlan et al., 1986a) using inhibin of $M_{\mathrm{r}} 58000$ and 31000 as antigen and tracer respectively.

Cyclic AMP in the follicular fluids was measured using a competitive protein binding assay as described by Brown et al. (1971), utilizing $\left[{ }^{3} \mathrm{H}\right] \mathrm{cAMP}$. Sensitivity was $5 \mathrm{pmol} / \mathrm{ml}$ and intra- and inter-assay coefficients of variation were 15 and $17 \%$ respectively.

\section{Results and Discussion}

\section{Oestradiol and progesterone in follicular fluid}

Concentrations of oestradiol and progesterone in human follicular fluid have been described in follicles from different stages of the cycle (McNatty et al., 1975), in follicles of different sizes (Westergaard et al., 1986), after the spontaneous LH surge (Edwards et al., 1980; Testart et al., 1983) and after an ovulatory injection of hCG in otherwise unstimulated (Bomsel-Helmreich et al., 1979 ) or mildly hyperstimulated (Templeton, 1985) women. In addition there are numerous reports of follicular fluid steroid concentrations following hyperstimulation with exogenous gonadotrophins for in-vitro fertilization. Although most authors are in agreement about the order of magnitude of the steroid concentrations, only the studies of Bomsel-Helmreich et al. (1979), Testart et al. (1983) and Templeton (1985) are able to give any indication of the qualitative nature of the concentration changes over the $35 \mathrm{~h}$ from the start of the LH surge until the point of ovulation. Even these studies suffer from the disadvantages of either small numbers (Testart et al., 1983) or that the changes follow administration of hCG to mimic the LH surge, rather than the spontaneous LH surge itself (Templeton, 1985). Firstly, it is not clear whether hCG can in fact mimic exactly all of the follicular changes induced by a spontaneous LH surge and, secondly, hCG given in this way to assist timing of ovulatory events must precede the spontaneous LH surge and therefore the follicles are being exposed to hCG at an earlier time than they would have been exposed to endogenous LH. Such differences may be irrelevant from the point of view of subsequent oocyte recovery for in-vitro fertilization, but they will undoubtedly distort the natural sequence of events that would occur around the start of a spontaneous surge.

The qualitative changes in the concentrations of oestradiol and progesterone from the spontaneous follicles in our study are shown in Fig. 1 while mean concentrations are given in Table 1. As already stated, each follicular fluid sample was allocated to an age group, based on the time from the onset of the LH surge. Within groups however, they have been ranked in order of descending oestradiol concentrations.

Oestradiol concentrations in the late preovulatory follicle just before or about the time of the LH surge are slightly higher than found by others (Bomsel-Helmreich et al., 1979; Testart et al., 1983; Templeton, 1985) and then fall slowly during the next $15 \mathrm{~h}$, more rapidly between 15 and $30 \mathrm{~h}$, and then more gradually again as the follicle ages. Concentrations recorded in the 'postovulatory' follicles $(>40 \mathrm{~h}$ ) are lower than the lowest concentrations recorded by others, but without indomethacin blockade it is extremely likely that these follicles would already have ovulated and thus would not have been measurable in other studies. From the work of Bomsel-Helmreich et al. (1979), it is clear that the large oestrogenic follicle is the healthy preovulatory follicle and the one that is destined to ovulate.

Progesterone concentrations in the early follicles before the LH surge are of the same order of magnitude as oestradiol concentrations at this time (Table 1), and this again confirms the work of others (Bomsel-Helmreich et al., 1979; Templeton, 1985). However, within a very short time of the start of the LH surge, progesterone concentrations rise rapidly and continue to do so for about the first $25 \mathrm{~h}$. At this point the rate of increase slows down, and concentrations seem to plateau at around $10000-12000 \mathrm{ng} / \mathrm{ml}$. This would be the time at which aspiration for in-vitro fertilization 

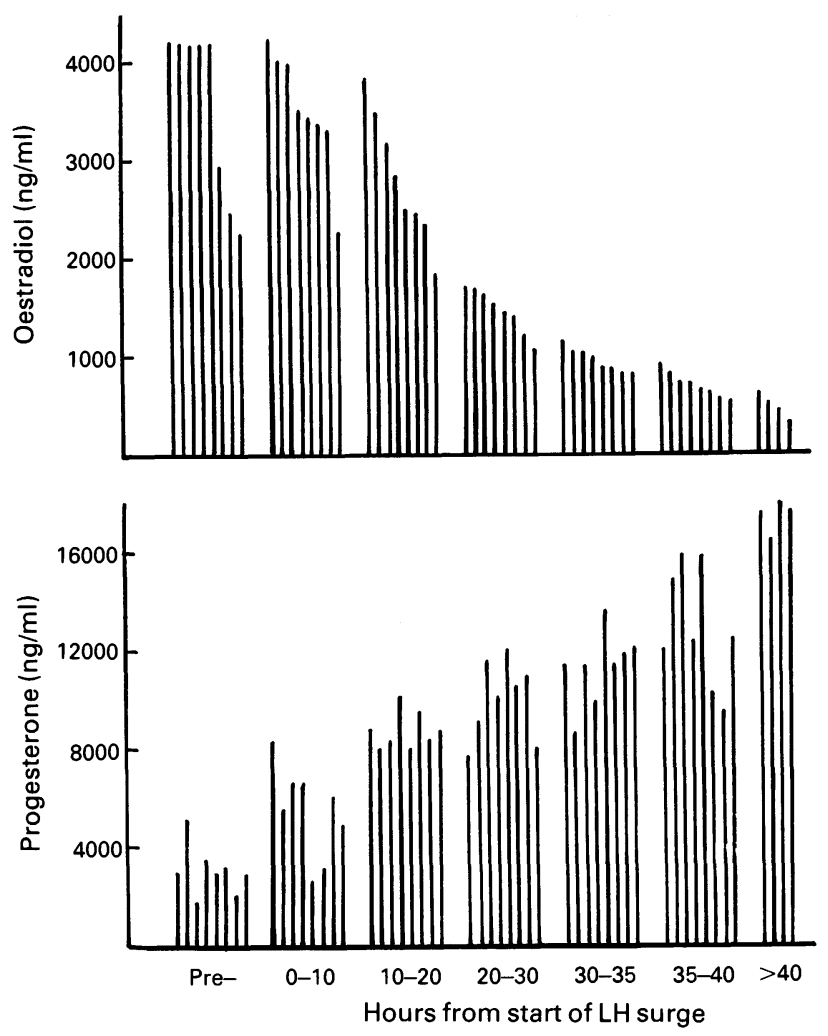

Fig. 1. Individual concentrations of oestradiol and progesterone in 44 follicular fluids obtained before or at different times after the start of the spontaneous LH surge (see text). The follicular fluids have been grouped into 7 age bands, but within each group fluids have been arbitrarily ranked in order of descending oestradiol concentrations. Throughout these and subsequent figures, the order of the follicular fluids is the same. Follicles aspirated at $>40 \mathrm{~h}$ from the start of the surge were those for which ovulation had failed to occur (indomethacin blockade in 3 and spontaneous luteinized unruptured follicle in 1). All follicular fluids were obtained during natural, unstimulated cycles.

would ideally take place and these progesterone concentrations are very similar to those recorded at this time by others $(18500 \mathrm{ng} / \mathrm{ml}$ : Edwards et al., 1980; $12000 \mathrm{ng} / \mathrm{ml}$ : Carson et al., 1982; $10000 \mathrm{ng} / \mathrm{ml}$ : Testart et al., 1983; $9400 \mathrm{ng} / \mathrm{ml}$ : Templeton, 1985).

Although the number of 'post-ovulatory' follicles was small, it would seem that, in these follicles, progesterone concentrations have increased sharply (to $17500 \mathrm{ng} / \mathrm{ml}$ ), although oestradiol concentrations have only fallen slightly. It may be of significance that plasma progesterone concentrations have also been shown to undergo a sudden increase at this time (Hoff et al., 1983; Djahanbackhch et al., 1984). These changes in circulating progesterone concentration have been taken to indicate ovulation, but if they are related to the late increase in progesterone synthesis seen in the 'post-ovulatory' follicle, then it is more likely that they reflect a time-dependent change in progesterone synthesis rather than follicular rupture per se. In view of the accelerating change in the oestrogen:progesterone ratio to which an oocyte retained within these follicles will be exposed, it will be of great interest to study the fertility potential of oocytes recovered from late or 'postovulatory' follicles, particularly as luteinized unruptured follicles are not uncommon in infertile women. 
Table 1. Mean concentrations ( \pm s.e.m.) of selected steroids and peptides in peripheral plasma, and in follicular fluid before and at intervals after the start of the spontaneous LH surge: all follicles were obtained during unstimulated cycles

\begin{tabular}{|c|c|c|c|c|c|c|c|}
\hline & \multirow{2}{*}{$\begin{array}{c}\text { Before } \\
\text { LH surge } \\
(n=8)\end{array}$} & \multicolumn{5}{|c|}{ Hours from LH surge } & \multirow{2}{*}{$\begin{array}{c}\text { Average } \\
\text { mid-cycle } \\
\text { peripheral } \\
\text { plasma } \\
\text { conc. }\end{array}$} \\
\hline & & $\begin{array}{c}0-10 \mathrm{~h} \\
(n=8)\end{array}$ & $\begin{array}{l}10-20 \mathrm{~h} \\
(n=8)\end{array}$ & $\begin{array}{l}20-30 \mathrm{~h} \\
(n=8)\end{array}$ & $\begin{array}{c}30-40 \mathrm{~h} \\
(n=16)\end{array}$ & $\begin{array}{l}>40 \mathrm{~h}^{*} \\
(n=4)\end{array}$ & \\
\hline $\begin{array}{l}\text { Steroids } \\
\text { Androstenedione } \\
\quad(\mathrm{ng} / \mathrm{ml}) \\
\text { Testosterone }(\mathrm{ng} / \mathrm{ml}) \\
\text { Oestradiol }(\mathrm{ng} / \mathrm{ml}) \\
\text { Progesterone }(\mathrm{ng} / \mathrm{ml})\end{array}$ & $\begin{aligned} 1280 & \pm 16 \\
110 & \pm 10 \\
3730 & \pm 360 \\
2900 & \pm 380\end{aligned}$ & $\begin{aligned} 190 & \pm 40 \\
45 & \pm 4 \\
3580 & \pm 270 \\
5410 & \pm 710\end{aligned}$ & $\begin{array}{c}180 \pm 30 \\
52 \pm 12 \\
2790 \pm 230 \\
8650 \pm 260\end{array}$ & $\begin{aligned} 200 & \pm 50 \\
39 & \pm 4 \\
1450 & \pm 80 \\
9880 & \pm 580\end{aligned}$ & $\begin{aligned} 170 & \pm 22 \\
28 & \pm 2 \\
810 & \pm 45 \\
12200 & \pm 530\end{aligned}$ & $\begin{array}{c}150 \pm 40 \\
37 \pm 8 \\
450 \pm 60 \\
17400 \pm 350\end{array}$ & $\begin{array}{l}6 \cdot 0 \\
0 \cdot 6 \\
0 \cdot 3 \\
1 \cdot 0\end{array}$ \\
\hline $\begin{array}{l}\text { Peptides } \\
\text { LH (U/l) } \\
\text { FSH (U/l) } \\
\text { Inhibin (U/mg) } \\
\text { Prolactin (U/l) }\end{array}$ & $\begin{array}{l}2.4 \pm 0.4 \\
1 \cdot 8 \pm 0 \cdot 3 \\
9 \cdot 9 \pm 1 \cdot 3 \\
390 \pm 30\end{array}$ & $\begin{array}{r}2 \cdot 4 \pm 0 \cdot 4 \\
2 \cdot 0 \pm 0 \cdot 3 \\
13 \cdot 5 \pm 2 \cdot 5 \\
280 \pm 13\end{array}$ & $\begin{array}{c}7 \cdot 6 \pm 13 \\
3 \cdot 3 \pm 0 \cdot 5 \\
11 \cdot 3 \pm 1 \cdot 3 \\
360 \pm 30\end{array}$ & $\begin{array}{r}15 \cdot 2 \pm 1 \cdot 5 \\
4 \cdot 9 \pm 0 \cdot 3 \\
9 \cdot 1 \pm 0 \cdot 8 \\
330 \pm 20\end{array}$ & $\begin{array}{r}13 \cdot 6 \pm 1 \cdot 1 \\
6 \cdot 4 \pm 0 \cdot 6 \\
9 \cdot 3 \pm 1 \cdot 0 \\
390 \pm 32\end{array}$ & $\begin{array}{l}7 \cdot 4 \pm 0 \cdot 5 \\
8 \cdot 1 \pm 2 \cdot 4 \\
6 \cdot 9 \pm 2 \cdot 3 \\
400 \pm 6 \cdot 0\end{array}$ & $\begin{array}{r}38 \cdot 0 \\
12 \cdot 5 \\
- \\
180\end{array}$ \\
\hline $\begin{array}{l}\text { cAMP } \\
\text { Mean conc. (nmol/l) } \\
\text { Follicles with } \\
\text { detectable levels }(\%)\end{array}$ & $\begin{array}{c}61 \pm 12 \\
100\end{array}$ & $\begin{array}{c}50 \pm 8 \\
100\end{array}$ & $\begin{array}{c}33 \pm 15 \\
50\end{array}$ & $\begin{array}{c}14 \cdot 5 \pm 5 \cdot 0 \\
38\end{array}$ & $\begin{array}{c}10 \cdot 6 \pm 4 \cdot 0 \\
19\end{array}$ & $\begin{array}{c}5 \cdot 8 \pm 0 \cdot 7 \\
12\end{array}$ & \\
\hline
\end{tabular}

*Ovulation (follicular rupture) was artificially delayed (by giving indomethacin) in 3 out of the 4 women whose follicular fluids were not recovered until $>40 \mathrm{~h}$ from the start of the spontaneous LH surge.

Finally, it should be noted that the magnitude of the changes in progesterone synthesis are much greater than those shown by oestradiol. From a biological point of view it becomes important to consider the following questions. (i) Do the falling oestradiol concentrations reflect metabolism, sequestration or secretion into the general circulation? (ii) What is the function of the relatively enormous (compared with the amounts required by the secretory endometrium or implicated in LH feedback in the luteal phase) progesterone concentrations? (iii) Are there obvious sequelae for the follicle cells exposed to these large steroid levels? For example is progesterone free in follicular fluid or bound (see Fleming \& McGaughey, 1982)? (iv) At follicular rupture does the $50 \mu \mathrm{g}$ or so of progesterone and $5 \mu \mathrm{g}$ of oestradiol (assuming a follicle with a volume of $5 \mathrm{ml}$ ) that is suddenly released into the peritoneal cavity have any physiological function?

\section{Androstenedione and testosterone}

Androstenedione, testosterone or total androgen concentrations in human follicular fluids have been described (Edwards et al., 1980; Brailly et al., 1981; Hillier et al., 1981; Carson et al., 1982; Testart et al., 1983; Templeton, 1985; Westergaard et al., 1986) but there is little uniformity in the actual concentrations recorded, nor is there a consensus on the qualitative changes to be expected after the LH surge (see Westergaard et al., 1986). In general it is considered that all small follicles are androgenic regardless of whether they are destined to ovulate or become atretic. Since granulosa cell number and proliferation rates are variable amongst small androgenic follicles it must be assumed that their intrafollicular milieu reflects thecal cell steroid synthesis. However, the two-cell theory of follicular steroidogenesis dictates that FSH acting on the granulosa cells of small follicles is able to stimulate aromatization of thecal-derived androgens to oestrogens. FSH and oestradiol within the follicle synergize to promote granulosa cell proliferation and thus more oestradiol production. High oestrogen concentrations co-existing with low androgen concentrations are considered to reflect healthy follicles (McNatty, 1982). Androgen synthesis by the theca interna is 

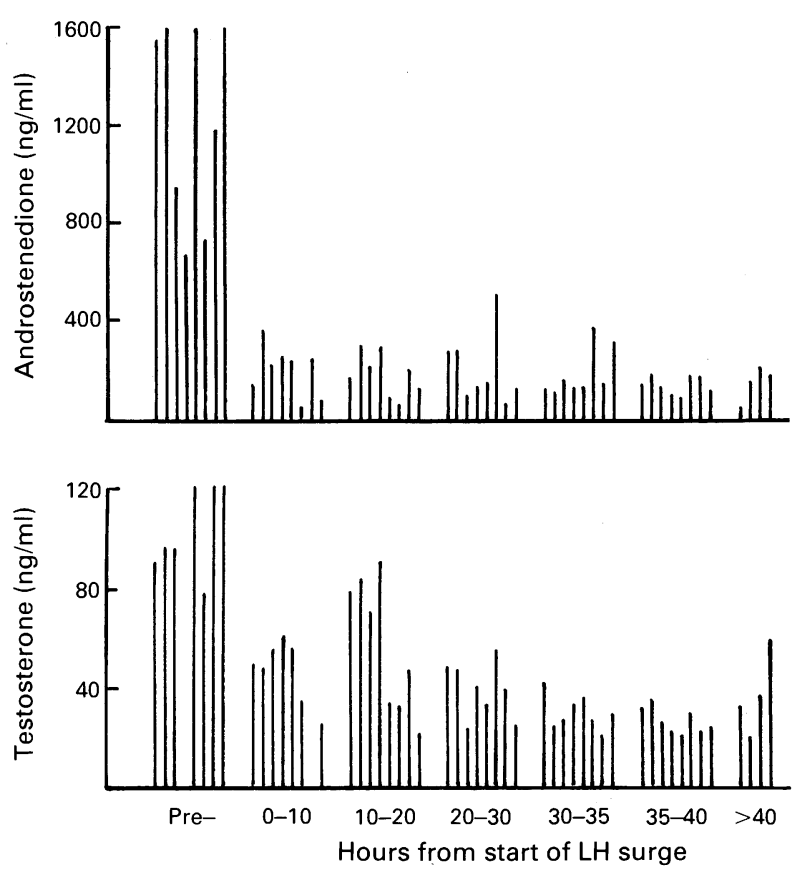

Fig. 2. Individual concentrations of androstenedione and testosterone in 44 follicular fluids obtained before or at different times after the start of the spontaneous LH surge. (See legend of Fig. 1 for details.)

thought to be regulated by $\mathrm{LH}$ and even though the exact sequence of change at the time of the $\mathrm{LH}$ surge is not well established, the end result is a change in the status of the follicle from oestrogenic to progestagenic.

Analysis of the follicular fluids from the present series for both androstenedione and testosterone gave the results shown in Fig. 2 and Table 1. Having established that all of the follicles in this series were oestrogenic (and therefore presumably healthy as opposed to atretic) it is difficult to reconcile our finding of very high androstenedione values before the LH surge with the data of others. Apart from McNatty et al. (1979a) and Westergaard et al. (1986) who reported mean androstenedione concentrations of $692-1050 \mathrm{ng} / \mathrm{ml}$ in healthy preovulatory follicles in the late follicular phase, and in selected highly oestrogenic follicles from the series of Hillier et al. (1981) and Westergaard et al. (1984), other groups consider mean androstenedione concentrations of $268 \mathrm{ng} / \mathrm{ml}$ (Brailly et al., 1981) and $321 \mathrm{ng} / \mathrm{ml}$ (Templeton, 1985) appropriate for follicles not yet exposed to LH-hCG. After an endogenous surge or hCG injection, androstenedione concentrations fall to a mean of $68 \mathrm{ng} / \mathrm{ml}$ (Brailly et al., 1981), $95 \mathrm{ng} / \mathrm{ml}$ (Templeton, 1985) or $28 \mathrm{ng} / \mathrm{ml}$ (Edwards et al., 1980). In hyperstimulated women, concentrations after the post-ovulatory stimulus were clearly higher at $300 \mathrm{ng} / \mathrm{ml}$ (Carson et al., 1982) and $500 \mathrm{ng} / \mathrm{ml}$ (Kerin et al., 1985).

Aside from the quantitative differences between the data presented here and those in some other reports, it is also important to consider the qualitative changes. Assuming that the data on the follicular oestradiol and progesterone concentrations (Fig. 1) correctly indicate active preovulatory follicles, as was suggested from the plasma $\mathrm{LH}$ and oestradiol measurements made to establish the stage of the cycle, then the clearly elevated androstenedione concentrations before the LH surge which declined rapidly with the start of the surge must have some biological significance. It is reassuring that similar changes are seen in intrafollicular testosterone concentrations, although, as would be expected for a steroid that is further down the synthetic pathway, the changes are not so acute. The changes in follicular oestradiol (Fig. 1) are seen to be lagging a few hours behind those of 
testosterone, again supporting the concept of a steroid cascade moving from cholesterol through progesterone to androstenedione ( \pm testosterone) within the theca. The androgen is then transferred to the granulosa in order to complete the synthetic pathway, androstenedione to testosterone to oestradiol.

It should be noted that intrafollicular concentrations of androstenedione and testosterone are much lower than those of oestradiol. This supports the concept that they are merely intermediary in the pathway to oestradiol. If the dramatic decline in androstenedione shown here can be verified (and see Dieleman et al., 1983a, for the cow), then the implications for the control of the switch in follicular biosynthesis from oestrogens to progesterone are numerous. It is already established that even after natural cessation of oestrogen synthesis, granulosa cells still have the ability to secrete the steroid provided they are supplied with androgen substrate (Hillier et al., 1981). It would therefore appear that the regulatory system does not reside at the level of aromatase (i.e. the conversion of testosterone to oestradiol). By implication then, it is the depletion of utilizable substrate that causes the decline in follicular oestradiol secretion. From our data it would seem that the depletion of androgen is a rapid and early event and this tends to suggest that it is regulated within the thecal cell layer rather than within the follicle by the granulosa cell (Dieleman et al., 1983a). There are a number of possibilities such as an LH-induced inhibition of androstenedione synthesis or alternatively a blockade of androstenedione transport across the basement membrane. This latter possibility seems quite likely as plasma androstenedione (and testosterone) concentrations decline rather more slowly but within same sequence androstenedione-testosterone-oestradiol than do intrafollicular levels (Djahanabackhch et al., 1984; Hoff et al., 1983). McNatty et al. (1979b) and Channing (1980) amongst others consider that the major portion of the peripheral plasma oestradiol concentration is a consequence of thecal cell and not granulosa cell synthesis and secretion.

\section{Prolactin concentrations}

Little has been written on the concentration of prolactin in follicular fluid. McNatty et al. (1975) observed that prolactin was detectable in almost all follicular fluids (unlike FSH or LH) and that concentrations were significantly lower in the late follicular phase compared with all other stages of the cycle. Concentrations were, however, similar to expected plasma concentrations (although not to the actual plasma concentrations measured which were obtained during the stress of surgery). Cooke et al. (1983) observed that prolactin concentrations in follicular fluids from the late follicular phase were somewhat higher than equivalent preoperative plasma concentrations but correlated closely with the plasma levels $(r=0.85, P<0.001, n=22)$. In the present study different reagents (utilizing a monoclonal antibody) were used to measure prolactin. Concentrations in this assay are lower than those obtained with more familiar radioimmunoassays, but prolactin concentrations in follicular fluid were easily detectable (Fig. 3) and were relatively constant over the period of the LH surge. These concentrations are about twice the normal plasma concentrations at that time of the cycle (Table 1), which suggests some form of selective uptake or concentration of prolactin within the follicle. It is unlikely that there is an intrafollicular source of prolactin since follicular fluids from patients treated with bromocriptine (Parlodel: Sandoz Products Ltd, Feltham, Middlesex TW13 4EP, U.K.) have undetectable follicular fluid prolactin concentrations (Cooke $e t$ al., 1983).

\section{FSH concentrations}

FSH is considered to be of crucial importance in the process of recruitment and selection of the dominant follicle due to its ability to stimulate aromatase activity in the granulosa cell which converts the follicular microenvironment from androgenic to oestrogenic (Westergaard et al., 1986). Furthermore, FSH is capable of stimulating aromatase activity in vitro, even after the LH 

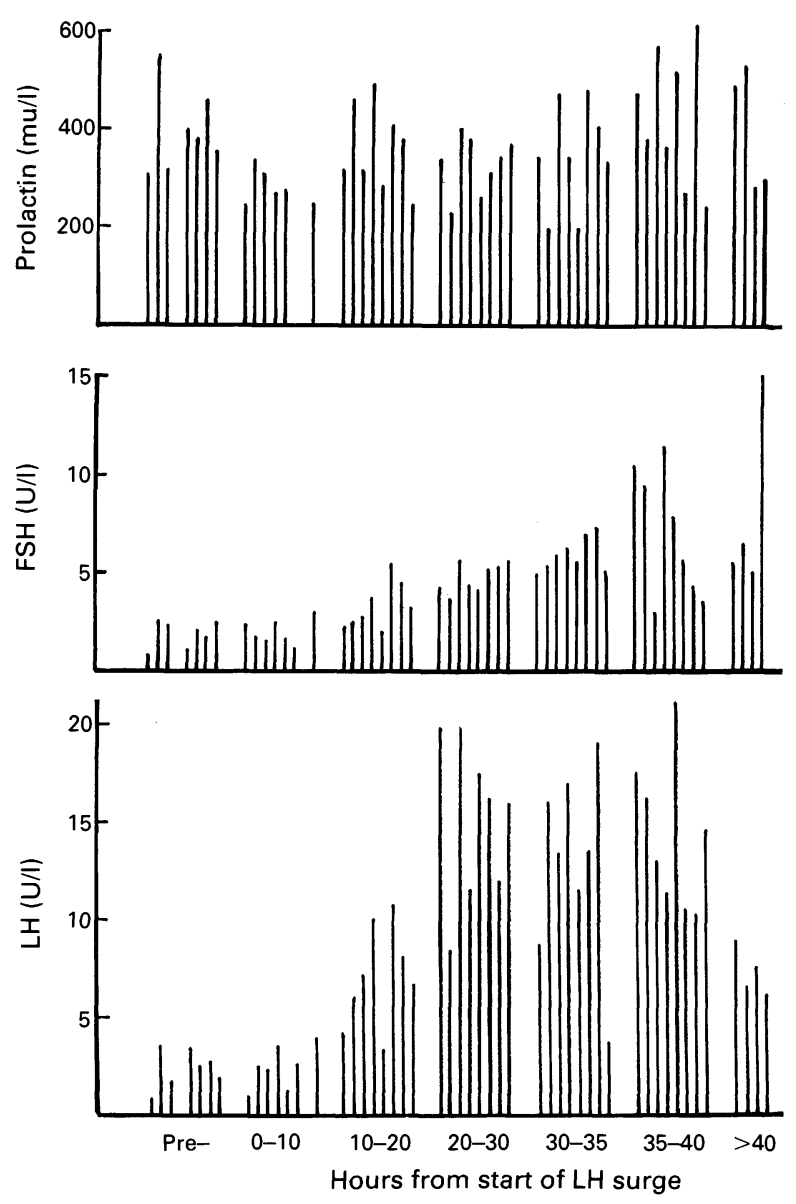

Fig. 3. Individual concentrations of prolactin, FSH and LH in 44 follicular fluids obtained before or at different times after the start of the spontaneous LH surge. (See legend of Fig. 1 for details.)

surge (Hillier et al., 1981). Despite these observations few studies have measured FSH concentrations directly (McNatty et al., 1979a, 1979b; Testart et al., 1983; Templeton, 1985) but when this has been done concentrations were found to be low (relative to plasma levels) even several hours after the start of the LH/hCG surge.

Recent availability of monoclonal antibody based FSH assays with improved sensitivity $(0.4 \mathrm{u} / 1)$ has prompted us to reconsider the qualitative and quantitative uptake of FSH by the follicle (Fig. 3; Table 1). Mean concentrations are low before and for some $10 \mathrm{~h}$ after the start of the $\mathrm{LH}$ surge, but then a gradual increase occurs such that by the time of expected ovulation, intrafollicular levels are about $50 \%$ of plasma values. These values agree closely with those of Testart et al. (1983) after a natural LH/FSH surge, and Templeton (1985) in whose study hCG was given instead of allowing a natural surge when it might be expected that endogenous peripheral FSH concentrations would not be elevated. In the earlier studies of McNatty et al. (1975) the sensitivity of the assays used was much lower (about $1.3 \mathrm{mU} / \mathrm{ml}$ ), but despite this $\mathrm{FSH}$ was detectable in a proportion of follicles examined, and the mean levels recorded are almost indistinguishable from the current ones once allowance is made for inclusion of undetectable samples in their group means. 


\section{LH concentrations}

LH concentrations in the follicles of the present study are shown in Fig. 3 and Table 1. The qualitative change across the LH surge is similar to FSH, and whilst concentrations are initially quite low, values start rising between 10 and $20 \mathrm{~h}$ to peak at 20-30 h. Plasma LH concentrations are also maximal at about this time (Djahanbakhch et al., 1984) although follicular fluid levels only ever attain about $40 \%$ of plasma levels. Despite the use here of a highly sensitive LH assay ( $0.4 \mathrm{u} / \mathrm{l})$ no immediate increase in follicular fluid LH was seen at the start of the LH surge. In fact levels at this time were uniformly low as described by others (McNatty et al., 1975; Testart et al., 1983).

An interesting aspect to the appearance of $\mathrm{LH}$ within the follicle is the observation that, from about $20 \mathrm{~h}$ after the $\mathrm{LH}$ surge, the basement membrane of the follicle starts to deteriorate (Bomsel-Helmreich et al., 1979) and morphological and functional luteinization becomes apparent (Dieleman et al., 1983b). It is at about this same time that LH (and FSH) start to appear within the follicle, and it is also the time when oestradiol concentrations are declining most rapidly. Perhaps, as suggested by Carson et al. (1986), entry of LH into the follicle is normally restricted, and it is only following an ovulatory dose of hCG (or LH) that follicular permeability is significantly increased and follicular LH and FSH concentrations rise gradually towards but never reaching the concentrations outside the follicle (Dieleman et al., 1983a).

\section{Relationship between FSH and inhibin}

The concentration of inhibin compared with the equivalent concentration of FSH in the 44 follicular fluids is shown in Fig. 4. Inhibin concentrations are highest in the follicles shortly after the start of the LH surge and then decline slightly. Although peak inhibin concentrations are seen at a time when oestradiol is maximal (McLachlan et al., 1986b), suggesting a granulosa cell source, the relative decline in the two compounds is quite dissimilar. However, over the period when inhibin concentrations are declining, intrafollicular FSH concentrations are rising slowly such that there is an inverse relationship between these two peptides (although the present data show this relationship rather poorly, a larger series of follicular fluids analysed for both hormones did give a significant inverse correlation: E. A. Lenton and R. I. McLachlan, unpublished observations).

Recent developments in understanding on inhibin physiology have suggested that the $\beta$ subunits of inhibin A and inhibin B combine to form $\beta$-dimers (FRP and activin) (Vale et al., 1986; Ling et al., 1986) which are active in stimulating the biosynthesis and release of FSH from pituitary cells in culture. The inhibin radioimmunoassay used here employed an antibody against inhibin of $M_{\mathrm{r}} 58000$ and showed $<5 \%$ cross-reactivity with bovine FRP. Furthermore, free $\alpha$ - and $\beta$ subunits showed no cross-reactivity in the assay. Consequently it is unlikely that the inhibin detected in follicular fluid could represent interfering $\beta$-dimers or free $\alpha$-subunit which, in the cow, is not found in follicular fluid (Miyamoto et al., 1986).

Some indirect evidence for the presence of $\beta$-dimers in these follicular fluids was, however, obtained when an attempt was made to confirm the radioimmunoassay concentrations by bioassay. After charcoal-dextran extraction (to remove the high amounts of steroid present) radioimmunoassayable inhibin concentrations also fell, suggesting that inhibin was being absorbed by the charcoal. In contrast, bioassayable concentrations paradoxically appeared to rise, suggesting that overall inhibin/ $\beta$-dimer ratio had been modified by charcoal extraction. For this reason no discussion of the function of inhibin in follicular fluid, or its relationship to FSH, will be complete until an assay is also available to measure the $\beta$-dimer concentrations.

\section{Relationship between $\mathrm{LH}$ and progesterone}

Whereas the decrease in oestradiol concentration in follicular fluid has been attributed to changes in aromatase activity or, the explanation more currently favoured, to depletion of androgen substrate, it has been tentatively assumed that the increase in progesterone was a consequence 

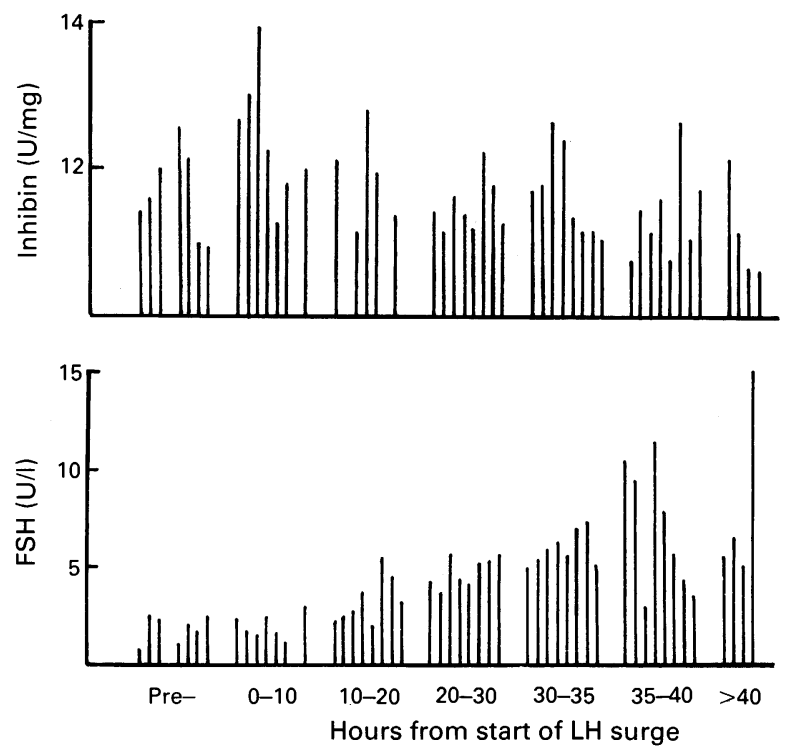

Fig. 4. Individual concentrations of inhibin in 44 follicular fluids related to simultaneous FSH concentrations obtained before or at different times after the start of the spontaneous LH surge. (See legend of Fig. 1 for details.)

of direct LH stimulation. From a visual comparison of the progesterone profile (Fig. 1) and the LH profile (Fig. 3) and remembering that these are exactly the same follicular fluids, it is obvious that the changes in progesterone are well advanced before any LH is detectable in the follicular fluid. Other explanations must therefore be sought. It is possible that $\mathrm{LH}$ does not reach the follicular fluid until uptake by the granulosa cell layer is saturated (Dieleman et al. (1983a). Whilst remaining a possibility, this seems somewhat unlikely since most small proteins that can easily enter the follicle are found in significant concentrations in follicular fluid (Anderson et al., 1976). Another possibility is that testosterone or oestradiol can selectively inhibit the intrafollicular conversion of cholesterol to progesterone (Batta et al., 1980; Veldhuis et al., 1983). For such a mechanism to regulate progesterone secretion, testosterone and/or oestradiol concentrations would need to decline before and not contemporaneously with the increase in progesterone. Although it is clear that there is an inverse relationship between testosterone and possibly oestradiol, and progesterone (Figs $1 \& 2$ ), this mechanism appears insufficiently precise to account solely for the increase in progesterone associated with the onset of the LH surge.

One further possibility (and there may well be numerous others) that has been examined in the present study is the relationship between changes in follicular hormone concentrations and cAMP (see Moor et al., 1975).

\section{Cyclic AMP in follicular fluid}

cAMP has been postulated as the second messenger involved in the transmission of LHmediated events (see review by Marsh, 1976). Certainly the morphological changes associated with luteinization in the granulosa cells can be induced by cAMP (Soto et al., 1986). In many species cAMP has also been considered to have a role in oocyte maturation (see later discussion). Follicular fluid cAMP concentrations have been measured after hyperstimulation for in-vitro fertilization and significantly lower values are found in follicles yielding fertilized or cleaved oocytes than in those oocytes which did neither (Tarlatzis et al., 1985). Apart from these data little appears to be known about in-vivo concentrations of cAMP in human follicles. 


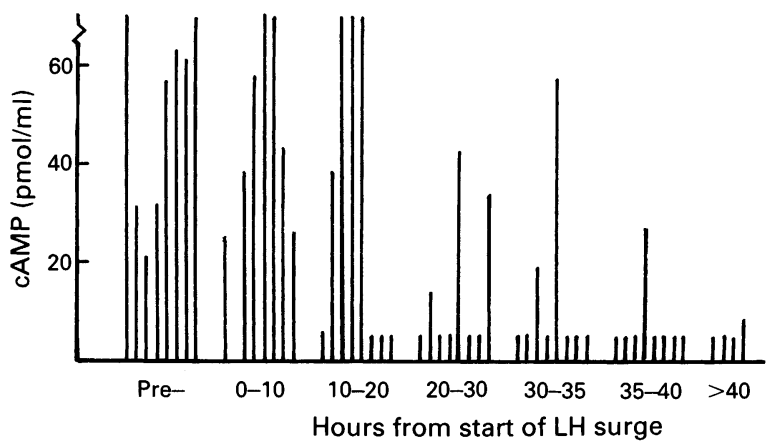

Fig. 5. Individual concentrations of cAMP in 44 follicular fluids related to simultaneous FSH concentrations obtained before or at different times after the start of the spontaneous LH surge. (See legend of Fig. 1 for details.)

cAMP was measured in all the follicles in the present study as shown in Fig. 5 and Table 1 but was only detected (at a concentration $>5 \mathrm{pmol} / \mathrm{ml}$ ) in some of the fluids. It appeared that the percentage of follicles with detectable levels was related to the time since the onset of the LH surge. In the early follicles (up to $10 \mathrm{~h}$ from the $\mathrm{LH}$ surge) $100 \%$ of the fluids had measurable cAMP concentrations. This figure declined to $50 \%$ (between 10 and $20 \mathrm{~h}$ ), to $38 \%$ (between 20 and $30 \mathrm{~h}$ ) and to $19 \%$ (between 30 and $40 \mathrm{~h}$ ). Mean concentrations also declined (Table 1) although the degree may well have been underestimated since all fluids in which cAMP was not detectable were assumed to have a concentration of $5 \mathrm{pmol} / \mathrm{ml}$ for the purpose of calculating the mean.

The marked change in intrafollicular cAMP concentrations from high levels present in all follicles even before the start of the LH surge to low/undetectable concentrations in the majority of follicles older than $20 \mathrm{~h}$ was unexpected, but seems too clear to be fortuitous. The reason for the progressive reduction in cAMP in older follicles is presently unknown although it could be due to an increase in phosphodiesterase activity. There was no phosphodiesterase activity present in an early follicular fluid, but a systematic check on follicles of all ages has not yet been performed.

\section{The relationship of $c A M P$ to $L H$}

As mentioned above, cAMP is thought to mediate the actions of LH. Certainly ovarian levels of cAMP rise rapidly in response to hCG (Dennefors et al., 1982). In the rabbit this response appeared to be biphasic (Goff \& Major, 1975) but even so concentrations had fallen markedly by $8 \mathrm{~h}$ (ovulation in the rabbit occurs at 10-12 h). Comparison of the qualitative changes in cAMP and LH shown here (Figs $3 \& 5$ ) suggests an inverse relationship between the two compounds. However, this would not be surprising if cAMP was indeed the second messenger, transmitting the LH stimulus to the granulosa cells within the follicle shortly after the start of the LH surge. An essential part of this hypothesis would be that cAMP should be secreted by the thecal cells and then rapidly move across the basement membrane to reach the granulosa cells (and of course the oocyte and cumulus cells).

There is good evidence that theca cells respond more directly to $\mathrm{LH} / \mathrm{hCG}$ with secretion of cAMP than do granulosa cells (Dennefors et al., 1982; Fletcher et al., 1983) and indeed that any cAMP detected in intact follicles in culture is a result of transmission from the thecal compartment (Weiss et al., 1976; Fletcher et al., 1983). Degradation of secreted cAMP is presumed to occur (by membrane-bound phosphodiesterase) but it is postulated (Moor \& Seamark, 1986) that sufficient cAMP may remain to stimulate granulosa cells to release more cAMP which serves to amplify the signal. The data presented here strongly support a thecal derivation of secretion; (i) magnitudes of the follicular changes are similar to those of androstenedione and testosterone, which mainly derive from the theca; (ii) the rapidity of the changes precedes any intrafollicular alteration in $\mathrm{LH}$; and (iii) there is evidence that thecal cAMP production becomes refractory to continued stimulation by 
hCG (Dennefors et al., 1983) in the same way that thecal androstenedione and testosterone synthesis are terminated after the LH surge. The remarkable similarity between the intrafollicular profiles of testosterone and cAMP (Figs $2 \& 5$ ) reinforces the impression that both compounds are produced by the same source (thecal cells), responding to the same signal (LH) and are following a similar time dependent course (see Moor et al., 1975).

\section{The endocrine environment and oocyte maturation}

Briefly, oocyte maturation can be considered to consist of three separate and independently regulated processes, namely nuclear, cytoplasmic and cumulus maturation. These components of the maturation process have been extensively reviewed elsewhere (McGaughey, 1983; Tsafriri, 1985; Yoshimura \& Wallach, 1987) but discussion of the endocrine environment of the oocyte would be incomplete without an attempt to set the above endocrine changes in the context of meiotic maturation.

There are subtle differences in the regulation of oocyte maturation in amphibians and most domestic species compared with man, not least of which is the timing of various aspects of maturation. In the human these events are, for nuclear maturation; approximately $25 \mathrm{~h}$ for germinal vesicle breakdown (GVBD), 28-30 h for extrusion of the first polar body and $32 \mathrm{~h}$ for arrest in metaphase II; for cytoplasmic maturation; approximately $30-40 \mathrm{~h}$ for migration of cortical granules within the oocyte and for cumulus maturation; approximately $25 \mathrm{~h}$ for expansion and $25-30 \mathrm{~h}$ for breakdown of intercellular communications. Crude though these timings are, they do illustrate two important features, the first is that the earliest visible signs of oocyte maturation are not perceived until about $25 \mathrm{~h}$, and secondly that all aspects of maturation are proceeding independently but within a closely similar time course. Thus any intrafollicular signals associated with the initiation of maturation would need to be present by $25 \mathrm{~h}$. In fact by this time oestradiol concentrations have already fallen markedly and progesterone concentrations have plateaued at a high level, and so the oestradiol:progesterone ratio which, before the LH surge, was approximately 1:1 will by now have reached 1:15. Cytoplasmic maturation is considered to be a consequence of changes in steroid balance within the follicle (Osborn \& Moor, 1983) which are indirectly attributable to the LH surge.

From about $25 \mathrm{~h}, \mathrm{FSH}$ begins to enter the follicle in increasing amounts. FSH suppresses intercellular coupling (Moor et al., 1981) and is thought to promote the secretion of glycosaminoglycans (GAGs) from granulosa cells (Yanagishita et al., 1981). These proteins are probably involved in maturation of the cumulus.

cAMP has long been considered to be a likely candidate as the second messenger, or distant activator for LH (Moor \& Seamark, 1986) but equally it is well known that high intra-oocyte cAMP levels inhibit resumption of meiosis (Eppig \& Downs, 1984). It has been assumed that the oocyte takes up cAMP from its surrounding cumulus cells, and therefore with advancing cumulus maturation intercellular communications decline, allowing intra-oocyte cAMP concentrations to fall and nuclear maturation to commence (Dekel \& Beers, 1978). Unfortunately for this hypothesis, nuclear maturation in the sheep (Moor \& Heslop, 1981) occurs even when cAMP levels are high and before signs of breakdown in intercellular communication. Furthermore, GVBD in the sheep follicle is not inhibited by cholera toxin (a potent stimulator of cAMP) until concentrations become so high that there is a direct toxic effect (Crosby et al., 1985). An alternative hypothesis is that cAMP stimulates production of a maturation inhibitor from cumulus cells, and it is the inhibitor rather than cAMP which is transferred to the oocyte (Freter \& Schultz, 1984).

Whether or not a reduction in oocyte cAMP is obligatory for the resumption of meiosis in mammals, it appears, at least in the human, that follicular fluid cAMP levels decline spontaneously several hours before the expected time of GVBD. Whether this decline is due to degradation (by phosphodiesterase), efflux from an increasingly 'leaky' follicle or desensitization (down regulation) of synthesis and production, as in the case of testosterone, is not known. In any event, it seems 
likely that nuclear maturation starts in response to a release from inhibition, such as when oocytes are removed prematurely from the follicle following a minimum but mandatory period within the follicle (Eppig, 1978). Factors associated with inhibition may be numerous and synergistic (e.g. OMI or MIS: Westergaard et al., 1984; Winer-Sorgen et al., 1986; hypoxanthine: Downs \& Eppig, 1986) and of course both cAMP and testosterone itself have been implicated (Rice \& McGaughey, 1981; Racowsky, 1983; Yoshimura \& Wallach, 1987).

\section{Conclusions}

The present discussion of some of the endocrine changes occurring within the follicle over the last $40 \mathrm{~h}$ before ovulation is far from comprehensive. For example, no data on the important prostaglandin changes have been included. However, it is hoped that the approach described here, whereby the start of the LH surge is assessed by frequent urine or plasma measurements, and this assessment of the 'age' of the follicle corroborated by the relative ratio of oestradiol to progesterone concentrations, will serve as a useful model in which to assess the dynamic equilibrium existing within the human follicle. Information obtained using this model should allow the components of the intrafollicular milieu to be categorized with respect to their functional role within the follicle. For example, some compounds such as collagenase may have primarily a facilitatory role whilst others such as cAMP may have a direct signalling role. The chronological changes in these compounds could then in turn be correlated with morphological and functional changes in the granulosa, basement membrane, and most importantly, the oocyte itself. Eventually it may be possible to go further and locate the biochemical abnormality in specific types of infertility (e.g. the luteinized unruptured follicle syndrome) or when the oocyte fails to undergo normal embryo development, with the ultimate goal of providing rational methods of treatment for these conditions.

We thank Carol Colman, Catherine Gelsthorpe, Lynne McTighe, Sarah Whyte and Linda Highfield for expert technical and secretarial assistance; Jeremy Osborn for constructive criticism and helpful advice during the preparation of this manuscript; and the Department of Anatomy, Monash University, for the inhibin measurements.

\section{References}

Anderson, M.M., Kroll, J., Byskov, A.G. \& Faber, M. (1976) Protein composition in the fluid of individual bovine follicles. J. Reprod. Fert. 48, 109-118.

Batta, S.K., Coulston Wentz, A. \& Channing, C.P. (1980) Steroidogenesis by human ovarian cell types in culture: influence of mixing of cell types and effect of added testosterone. J. clin. Endocr. Metab. 52, 274-279.

Bomsel-Helmreich, O., Gougeon, A., Thebault, A., Saltarelli, D., Milgrom, E., Frydman, R. \& Papiernik, E. (1979) Healthy and atretic human follicles in the preovulatory phase: differences in the evolution of follicular morphology and steroid content of follicular fluid. J. clin. Endocr. Metab. 48, 686-694.

Brailly, S., Gougeon, A., Milgrom, E., Bomsel-Helmreich, O. \& Papiernik, E. (1981) Androgens and progestins in the human ovarian follicle: differences in the evolution of preovulatory, healthy nonovulatory and atretic follicles. J. clin. Endocr. Metab. 53, 128-134.

Brown, Bh., Albano, J.D.M., Elkins, R.P. \& Sgherzi, A.M. (1971) A simple and sensitive saturation assay method for measurement of adenosine $3^{\prime}, 5^{\prime}$ cAMP. Biochem. J. 121, 561-562.
Carson, R.S., Trounson, A.O. \& Findlay, J.K. (1982) Successful fertilisation of human oocytes in vitro: Concentration of oestradiol 17- $\beta$, progesterone and androstenedione in the antral fluid of donor follicles. J. clin. Endocr. Metab. 55, 798-800.

Carson, R.S., Salamonsen, L.A. \& Findlay, J.K. (1986) Permeability of rat ovarian follicles to LH during development and luteinisation. J. Reprod. Fert. 76, 663-676.

Channing, C.P. (1980) Progesterone and estrogen secretion by cultured monkey ovarian cell types: influences of follicular size, serum luteinizing hormone levels, and follicular fluid estrogen levels. Endocrinology 107, 342-352.

Cooke, I.D., Lenton, E.A., Tennekoon, K.H. \& Smith, S.K. (1983) Does prolactin have a physiological role in the modulation of cyclical human ovarian function? Proc. 11th Wld Congr. Fert. Steril., Dublin, Abstr. 412. Ed. R. F. Harrison. ETA Publications, Dublin.

Crosby, I.M., Moor, R.M., Heslop, J.P. \& Osborn, J.C. (1985) cAMP in ovine oocytes: localization of synthesis and its action on protein synthesis, 
phosphorylation and meiosis. J. exp. Zool. 234, 307-318.

Dekel, N. \& Beers, W.H. (1978) Rat oocytes maturation in vitro: relief of cyclic AMP inhibition by gonadotrophins. Proc. natn. Acad. Sci. U.S.A. 75, 4369-4373.

Dennefors, B.L., Nilsson, L. \& Hamberger, L. (1982) Steroid and adenosine $3^{\prime}, 5^{\prime}$-monophosphate formation in granulosa and thecal cells from human preovulatory follicles in response to human chorionic gonadotropin. J. clin. Endocr. Metab. 54, 436-441.

Dennefors, B.L., Hamberger, L. \& Nilsson, L. (1983) Influence of human chorionic gonadotropin in vivo on steroid formation and gonadotropin responsiveness of isolated human preovulatory follicular cells. Fert. Steril. 39, 56-61.

Dieleman, S.J., Bevers, M.M., Poortman, J. \& van Tol, H.T.M. (1983a) Steroid and pituitary hormone concentrations in the fluid of preovulatory bovine follicles relative to the peak of $\mathrm{LH}$ in peripheral blood. J. Reprod. Fert. 69, 641-649.

Dieleman, S.J., Kruip, Th.A.M., Fontijne, P., de Jong, W.H.R. \& Van der Weyden, G.C. (1983b) Changes in oestradiol, progesterone and testosterone concentrations in follicular fluid and in the micromorphology of pre-ovulatory bovine follicles relative to the peak of luteinising hormone. J. Endocr. 97, 31-42.

Djahanbakhch, O., McNeilly, A.S., Warner, P.M., Swanston, I.A. \& Baird, D.T. (1984) Changes in plasma levels of prolactin, in relation to those of FSH, oestradiol, androstenedione and progesterone around the pre-ovulatory surge in women. Clin. Endocr. 20, 463-472.

Downs, S.M. \& Eppig, J.J. (1986) Maintenance of murine oocyte arrest: uptake and metabolism of hypoxanthine and adenosine by cumulus cell-enclosed and denuded oocytes. Devl. Biol. 117, 174-183.

Edwards, R.G., Steptoe, P.C., Fowler, R.E. \& Baillie, J. (1980) Observations on preovulatory human ovarian follicles and their aspirates. Br. J. Obstet. Gynaec. 87, 769-779.

Eppig, J.J. (1978) Development potential of LT/SV parthenotes derived from oocytes matured in vivo and in vitro. Devl Biol. 65, 244-249.

Eppig, J.J. \& Downs, S.M. (1984) Chemical signals that regulate mammalian oocyte maturation. Biol. Reprod. 30, 1-12.

Fleming, A.D. \& McGaughey, R.W. (1982) A progesterone binding component in porcine ovarian follicular fluid. J. Endocr. 94, 69-76.

Fletcher, W.H., Tuso, P.J. \& Greenan, J.R.T. (1983) Gap junction mediation of hormone action that causes cAMP dependent protein kinase dissociation in ovarian granulosa cells. J. Cell Biol. 97, 80a, Abstr.

Freter, R.R. \& Schultz, R.M. (1984) Regulation of murine oocyte meiosis: evidence for a gonadotropininduced, cAMP-dependent reduction in a maturation inhibitor. J. Cell Biol. 98, 1119-1128.

Goff, A.K. \& Major, P.W. (1975) Concentrations of cyclic AMP in rabbit ovarian tissue during the preovulatory period and pseudopregnancy after induction of ovulation by administration of human chorionic gonadotropin. J. clin. Endocr. Metab. 54, 436-441.
Hillier, S.G., Reichert, L.E. \& Van Hall, E.V. (1981) Control of pre-ovulatory follicular estrogen biosynthesis in the human ovary. J. clin. Endocr. Metab. 52, 847-856.

Hoff, J.D., Quigley, M.E. \& Yen, S.S.C. (1983) Hormonal dynamics at mid-cycle: re-evaluation. $J$. clin. Endocr. Metab. 57, 792-796.

Kerin, J.F., Warnes, G.M., Broom, T.J., McEvoy, M., Godfrey, B., Quinn, P., Herriott, D. \& Cox, L.W. (1985) Evidence that post mature oocytes may reduce pregnancy rates following in vitro fertilisation and embryo transfer. Clin. Reprod. Fert. 3, 265, Abstr.

Lenton, E.A., Sawers, R.B. \& Zegers, F. (1985) Aspiration of the dominant follicle during the mid to late follicular phase of spontaneous cycles. In In Vitro Fertilisation and Donor Insemination, pp. 63-78. Eds W. Thompson, D. N. Joyce \& J. R. Newton. Royal College of Obstetricians and Gynaecologists, London.

Ling, N., Ying, S-Y., Ueno, N., Shimasaki, S., Esch, F., Hotta, M. \& Guillemin, R. (1986) Pituitary FSH is released by a heterodimer of the $\beta$-subunits from the two forms of inhibin. Nature, Lond. 321, 779-782.

McGaughey, R.W. (1983) Regulation of oocyte maturation. Oxford Rev. Reprod. Biol. 5, 106-130.

McLachlan, R.I., Robertson, D.M., Burger, H.G. \& de Kretser, D.M. (1986a) The radioimmunoassay of bovine and human follicular fluid and serum inhibin. Molec. cell. Endocr. 46, 175-185.

McLachlan, R.I., Robertson, D.M., Healy, D.L., de Kretser, D.M. \& Burger, H.G. (1986b) Plasma inhibin levels during gonadotropin-induced ovarian hyperstimulation for IVF: a new index of follicular function? Lancet 1233-1234.

McNatty, K.P. (1982) Ovarian follicular development from the onset of luteal regression in humans and sheep. In Follicular Maturation and Ovulation, pp. 1-8. Eds R. Rolland, E. V. Van Hall, S. G. Hillier, K. P. McNatty \& J. Shoemaker. Excerpta Medica, Amsterdam.

McNatty, K.P. \& Baird, D.T. (1978) Relationship between follicle-stimulating hormone, androstenedione and oestradiol in human follicular fluid. $J$. Endocr. 76, 527-531.

McNatty, K.P., Hunter, L.M., McNeilly, A.S. \& Sawers, R.S. (1975) Changes in the concentration of pituitary and steroid hormones in the follicular fluid of human Graafian follicles throughout the menstrual cycle. $J$. Endocr. 64, 555-571.

McNatty, K.P., Makris, A., De Grazia, C., Osathanondh, R. \& Ryan, K.J. (1979a) The production of progesterone, androgens and estrogens by granulosa cells, thecal tissue and stromal tissue from human ovaries in vitro. J. clin. Endocr. Metab. 49, 687-699.

McNatty, K.P., Makris, A., De Grazia, C., Osanthanodh, R. \& Ryan, K.J. (1979b) The production of progesterone, androgens and oestrogens by human granulosa cells in vitro and in vivo. J. Steroid Biochem. 11, $775-779$.

Marsh, J.M. (1976) The role of cyclic AMP in gonadal steroidogenesis. Biol. Reprod. 14, 30-53.

Miyamoto, K., Hasegawa, Y., Fukuda, M. \& Igarashi, M. (1986) Demonstration of high molecular weight forms of inhibin in bovine follicular fluid (bff) by 
using monoclonal antibodies to bFF $32 \mathrm{kDa}$ inhibin. Biochem. Biophys. Res. Commun. 136, 1103-1109.

Moor, R.M., Hay, M.F. \& Seamark, R.F. (1975) The sheep ovary: regulation of steroidogenic, haemodynamic and structural changes in the largest follicle and adjacent tissue before ovulation. J. Reprod. Fert. 45, 595-604.

Moor, R.M. \& Heslop, J.P. (1981) Cyclic AMP in mammalian follicle cells and oocytes during maturation. $J$. exp. Zool. 216, 205-209.

Moor, R.M., Osborn, J.C., Cran, D.G. \& Walter, D.E. (1981) Selective effect of gonadotrophins on cell coupling nuclear maturation and protein synthesis in mammalian oocytes. J. Embryol. exp. Morph. 61, $347-365$.

Moor, R.M. \& Seamark, R.F. (1986) Cell signalling, permeability and microvasculatory changes during antral follicle development in mammals. J. Dairy Science 69, 927-943.

Murdoch, W.J. \& Dunn, T.C. (1983) Luteal function after ovulation blockade by intrafollicular injection of indomethacin in the ewe. J. Reprod. Fert. 69, 671-675.

Osborn, J.C. \& Moor, R.M. (1983) The role of steroid signals in the maturation of mammalian oocytes. $J$. Steroid Biochem. 19, 133-138.

Racowsky, C. (1983) Androgenic modulation of cyclic adenosine monophosphate (cAMP)-dependent meiotic arrest. Biol. Reprod. 28, 774-787.

Rice, C. \& McGaughey, R.W. (1981) Effect of testosterone and dibutyryl cAMP on the spontaneous maturation of pig oocytes. J. Reprod. Fert. 62, $245-256$.

Soto, E.A., Kliman, H.J., Strauss, J.F., III \& Paavola, L.G. (1986) Gonadotropins and cyclic adenosine $3^{\prime}, 5^{\prime}$-monophosphate (cAMP) alter the morphology of cultured human granulosa cells. Biol. Reprod. 34, 559-569.

Tarlatzis, C., Laufer, N., De Cherney, A.H., Polan, M.L., Haseltine, P. \& Behrman, H.R. (1985) Adenosine 3',5'-monophosphate levels in human follicular fluid: relationship to oocyte maturation and achievement of pregnancy after in vitro fertilization. J. clin. Endocr. Metab. 60, 1111-1115.

Templeton, A.A. (1985) Ovulation timing and in vitro fertilisation. In In Vitro Fertilisation and Donor Insemination, pp. 241-251. Eds W. Thompson, D. N. Joyce \& J. R. Newton. Royal College of Obstetricians and Gynaecologists, London.
Testart, J., Frydman, R., Belaisch, J.C., Castanier, M., Feinstein, M.C., Grenier, J. \& Roger, M. (1983) Profil hormone plasmatique et intrafolliculair au cours de la période préovulatoire tardive. I Cycles spontanés. $J$. Gynaecol. Obstet. Biol. Reprod. (Paris) 12, 119-127.

Tsafriri, A. (1985) The control of meiotic maturation in mammals. In Biology of Fertilisation, vol. 1, pp. 221-252. Eds C. B. Metz \& A. Monroy. Academic Press, New York.

Vale, W., Rivier, J., Vaughan, J., McClintock, R., Corrigan, A., Woo, W., Karr, D. \& Spiess, J. (1986) Purification and characterisation of an FSH releasing protein from porcine ovarian follicular fluid. Nature, Lond. 321, 776-779.

Veldhuis, J.D., Klase, P.A., Sandow, B.A. \& Kolip, L.A. (1983) Progesterone secretion by highly differentiated human granulosa cells isolated from preovulatory Graafian follicules induced by exogenous gonadotropins and human chorionic gonadotropin. J. clin. Endocr. Metab. 57, 87-93.

Weiss, T.J., Seamark, R.F., McIntosh, J.E.A. \& Moor, R.M. (1976) Cyclic AMP in sheep ovarian follicles: site of production and response to gonadotrophins. J. Reprod. Fert. 46, 347-353.

Westergaard, L., Byskov, A.G., Anderson, C.Y., Grinsted, J. \& McNalty, K.P. (1984) Is resumption of meiosis in the human pre-ovulatory oocyte triggered by a meiosis-inducing substance (MIS) in the follicular fluid? Fert. Steril. 41, 377-384.

Westergaard, L., Christensen, I.J. \& McNatty, K.P. (1986) Steroid levels in ovarian follicular fluid related to follicle size and health status during normal menstrual cycle in women. Hum. Reprod. 1, 227-232.

Winer-Sorgen, S., Brown, J., Ono, T., Gale, J.A., Campeau, J.D., Marrs, R.P. \& Dizerega, G.S. (1986) Oocyte maturation inhibitor activity in human follicular fluid: quantitative determination in stimulated and clomiphene citrate-and human menopausal gonadotropin-stimulated ovarian cycles. $J$. in vitro Fert. Emb. Trans. 3, 218-223.

Yanagishita, M., Hascall, V.C. \& Rodbard, D. (1981) Biosynthesis of proteoglycans by rat granulosa cells cultured in vitro: modulation by gonadotrophins, steroid hormones, prostaglandins and a cyclic nucleotide. Endocrinology 109, 1641-1649.

Yoshimura, Y. \& Wallach, E.E. (1987) Studies of the mechanism(s) of mammalian ovulation. Fert. Steril. 47, 22-34. 